\title{
Psychological Well-Being and Type 2 Diabetes
}

\author{
Christina N Massey, Emily H Feig, Laura Duque-Serrano and Jeff C Huffman* \\ Department of Psychiatry, Massachusetts General Hospital, Harvard Medical School, USA
}

Submission: October 26, 2017; Published: October 30, 2017

*Corresponding author: Jeff C Huffman, Department of Psychiatry, Massachusetts General Hospital, Massachusetts General Hospital, 55 Fruit Street/Blake 11, USA, Tel: 617-724-2910; Fax: 617-724-9155; Email: jhuffman@partners.org

\begin{abstract}
Positive psychological characteristics such as optimism, positive affect, gratitude, and related constructs may play an important role in health. In patients with type 2 diabetes (T2D), positive psychological constructs have been associated with superior medical outcomes, including better glucose control and lower mortality rates. The beneficial effects of positive psychological states in T2D are most likely mediated through health behaviors such as increased physical activity and adherence to a healthier diet. Furthermore, numerous studies with non-diabetic populations have shown that performing various positive psychological exercises (e.g., writing gratitude letters, performing acts of kindness) have led to greater well-being. Compared to other available treatments, these activities are simple and involve constructs that have been associated with superior adherence and diabetes-related outcomes. However, there has been minimal research on the use of positive psychological interventions in T2D, though small studies of related interventions have been linked to improvements in positive affect and, in some cases, greater health behavior adherence and lower blood sugar. Continued work is needed to ascertain whether positive psychology interventions can truly impact functioning, blood sugar, and overall health in this key population.
\end{abstract}

Keywords: Diabetes; Positive psychology; Well-being; Positive affect; Positive psychology intervention; Optimism

Psychological distress and negative affective disorders are common in patients with type 2 diabetes (T2D). A substantial proportion of patients with T2D have clinical depression [1] and even those who do not meet full diagnostic criteria for a depressive disorder have substantial distress that can impede self-care, functioning across multiple domains (e.g., occupational, personal), and quality of life [2]. Psychological states may also significantly impact health behavior and clinical outcomes in patients with T2D [3]. Negative psychological syndromes such as depression and anxiety have been consistently associated with poor outcomes in patients with T2D [4-6]. For example, depression is associated with impaired glucose control [7], functional disability [8], end-organ complications [7], and mortality $[7,9,10]$, and distress itself is associated with lower levels of treatment adherence [2].

On the other hand, positive psychological characteristicsoptimism, positive affect, gratitude, and related constructsmay also play an important role in medical outcomes. These positive psychological constructs are not simply the flip-side of depression [11,12], e.g., it is possible that a depressed individual may be optimistic about the future whereas a non-depressed individual may conversely have low levels of optimism. Prior work has found that these constructs have been linked to superior health outcomes including healthier diet, increased physical activity, and lower rates of mortality across various medical conditions [13-15]. Furthermore, the connections between positive psychological constructs and health have been independent of sociodemographic factors, medical characteristics, and the adverse effects of depression and anxiety $[13,15]$. Nonetheless, there has been less focus on the promotion of positive psychological well-being in T2D individuals.

Specifically related to T2D, positive psychological constructs have been associated with numerous beneficial outcomes $[3,16-$ 18]. For example, in a large epidemiologic study, measures of psychological well-being, including emotional vitality and life satisfaction, were prospectively linked with the prevention of T2D [19]. Among patients who have developed T2D, positive psychological attributes are related to superior outcomes. For instance, overall well-being is correlated with better glucose control [20]. Likewise, resilience has been associated with lower levels of hemoglobin A1c, and such resilience has been shown to buffer the effects of psychological distress on blood sugar [21]. Finally, positive affect has been prospectively and independently linked to lower mortality among those with T2D [22]. 
Though the relationship of positive psychological constructs and health outcomes is not fully understood, the beneficial effects of positive psychological states are most likely mediated through health behaviors. Positive states in some studies have been directly associated with favorable effects on physiology in T2D (e.g., reduced sympathetic hyperactivity, decreased levels of proinflammatory biomarkers, and decreased hypothalamicpituitary-adrenal axis hyperactivity) [3,16-18]. However, most evidence that links positive states to superior outcomes does so via increased adherence to health behaviors [16-18]. For example, in T2D patients, positive affect and optimism have been prospectively linked to greater physical activity, healthier diet, and reduced smoking, even after controlling for baseline behavior and relevant covariates [22]. Such improvements in health behavior may be caused by easier initiation of physical activity, greater confidence in meeting diet and activity goals, and more vitality/energy to engage in self-management when experiencing positive mood [23].

An important question is whether positive psychological well-being is inherent or whether it can be modified. There is by now a substantial literature on so-called positive psychology (PP) interventions and their efficacy in improving psychological well-being. PP interventions use exercises (e.g., gratitude letters, acts of kindness, personal strengths), completed in a systematic manner, to boost optimism, positive affect, and resilience. In healthy participants, PP exercises have consistently increased well-being and decreased depression in studies of over 5000 participants [24]. More recently, trials in patients with coronary heart disease, hypertension, and HIV have found that such programs have had beneficial effects on well-being, depression, and in some cases, health behaviors [25-29].

PP interventions have several potential advantages to other treatment programs, particularly when considering individuals with T2D. First, as opposed to treatments that are applied only to patients with clinical depression or other psychiatric disorders, PP interventions are instead designed to increase positive psychological well-being across a variety of different populations, including those considered to be psychiatrically healthy [30]. This should make the PP intervention more applicable to individuals with T2D who may experience a range of psychiatric symptoms. PP also differs from somewhat-related mindfulnessbased stress reduction and self-efficacy interventions [31-33] in that it: (a) specifically targets constructs-positive affect and optimism-linked to superior adherence and outcomes in T2D [3], (b) utilizes validated PP exercises found to be effective across dozens of studies [24], and (c) is simple for patients and does not require the substantial provider training needed for most other interventions.

Despite the potential benefits of an intervention that could promote well-being, reduce distress, and improve self-care in T2D patients, there has been limited study of PP interventions in this patient population. However, results to date have yielded encouraging findings. For example, an online positive affect intervention for T2D patients led to improvements in positive affect and depression, although no significant changes in diabetes-specific efficacy or in health behaviors were found [34]. A related resilience-focused intervention for T2D patients was, however, associated with improvements in HDL cholesterol and fasting blood sugar in a small controlled trial [35], and a one-arm pilot study of a PP intervention also found substantial improvements in psychological outcomes and self-reported health behavior adherence [36].

In the context of these promising but mixed results in T2D patients, there is still a question about whether such PP interventions alone are enough to result in changes in selfcare and outcomes, or whether they are better combined with existing behavioral interventions. In the case of the latter scenario, the well-being component would presumably promote motivation, self-efficacy, and optimism, which would allow for greater engagement in the intervention. It is also still unknown how PP interventions compare to other behavioral interventions that have been tested in this population targeting self-efficacy or stress management, which have been shown to affect diabetesrelated distress $[37,38]$ and, less consistently, health outcomes [39-42]. Given the clear associations between well-being and outcomes in T2D, along with the promising effects of initial PPbased studies, continued work in this area is needed to ascertain whether well-being interventions can truly impact function, blood sugar, and overall health in this key population.

\section{Acknowledgements and Funding}

This work was supported in part by NIH grant R21DK109313-01 and American Diabetes Association Grant 1-17-ICTS-099 (Huffman PI). The authors have no conflicts of interest to report and there were no other funding sources.

\section{References}

1. Gonzalez JS, Safren SA, Cagliero E, Wexler DJ, Delahanty L, et al. (2007) Depression, self-care, and medication adherence in type 2 diabetes: relationships across the full range of symptom severity. Diabetes Care 30(9): 2222-2227.

2. Gonzalez JS, Shreck E, Psaros C, Safren SA (2015) Distress and type 2 diabetes-treatment adherence: a mediating role for perceived control. Health Psychol 34(5): 505-513.

3. Celano CM, Beale EE, Moore SV, Wexler DJ, Huffman JC (2013) Positive psychological characteristics in diabetes: a review. Curr Diabetes Rep 13(6): 917-929.

4. Anderson RJ, Freedland KE, Clouse RE, Lustman PJ (2001) The prevalence of comorbid depression in adults with diabetes: a metaanalysis. Diabetes Care 24(6): 1069-1078.

5. Li C, Barker L, Ford ES, Zhang X, Strine TW, et al. (2008) Diabetes and anxiety in US adults: findings from the 2006 Behavioral Risk Factor Surveillance System. Diabet Med 25(7): 878-881.

6. Niemcryk SJ, Speers MA, Travis LB, Gary HE (1990) Psychosocial correlates of hemoglobin Alc in young adults with type I diabetes. J Psychosom Res 34(6): 617-627. 


\section{Current Research in Diabetes \& Obesity Journal}

7. Lustman PJ, Clouse RE (2005) Depression in diabetic patients: the relationship between mood and glycemic control. J Diabetes Complications 19(2): 113-122.

8. Egede LE (2004) Diabetes, major depression, and functional disability among U.S. adults. Diabetes Care 27(2): 421-428.

9. Egede LE, Nietert PJ, Zheng D (2005) Depression and all-cause and coronary heart disease mortality among adults with and without diabetes. Diabetes Care 28(6): 1339-1345.

10.Zhang X, Norris SL, Gregg EW, Cheng YJ, Beckles G, et al. (2005) Depressive symptoms and mortality among persons with and without diabetes. Am J Epidemiol 161(7): 652-660.

11. Ryff CD, Love GD, Urry HL, Muller D, Rosenkranz MA, et al. (2006) Psychological well-being and ill-being: do they have distinct or mirrored biological correlates? Psychother Psychosom 75(2): 85-95

12. DuBois CM, Beach SR, Kashdan TB, Nyer MB, Park ER, et al. (2012) Positive psychological attributes and cardiac outcomes: associations, mechanisms, and interventions. Psychosomatics 53(4): 303-318.

13. Chida Y, Steptoe A (2008) Positive psychological well-being and mortality: a quantitative review of prospective observational studies. Psychosom Med 70(7): 741-756.

14. Giltay EJ, Geleijnse JM, Zitman FG, Buijsse B, Kromhout D (2007) Lifestyle and dietary correlates of dispositional optimism in men: the Zutphen Elderly Study. J Psychosom Res 63(5): 483-490.

15. Huffman JC, Beale EE, Celano CM, Beach SR, Belcher AM, et al. (2016) Effects of optimism and gratitude on physical activity, biomarkers, and readmissions after an acute coronary syndrome: the Gratitude Research in Acute Coronary Events study. Circ Cardiovasc Qua Outcomes 9(1): 55-63.

16. Al Khawaldeh OA, Al Hassan MA, Froelicher ES (2012) Self-efficacy, self-management, and glycemic control in adults with type 2 diabetes mellitus. J Diabetes Complications 26(1): 10-16.

17. Robertson SM, Stanley MA, Cully JA, Naik AD (2012) Positive emotiona health and diabetes care: concepts, measurement, and clinical implications. Psychosomatics 53(1): 1-12.

18. Venkataraman K, Kannan AT, Kalra OP, Gambhir JK, Sharma AK, et al. (2012) Diabetes self-efficacy strongly influences actual control of diabetes in patients attending a tertiary hospital in India. J Community Health 37(3): 653-662.

19. Boehm JK, Fitzgerald CT, Kivimaki M, Kubzansky LD (2015) The prospective association between positive psychological well-being and diabetes. Health Psychol 34(10): 1013-1021.

20. Papanas N, Tsapas A, Papatheodorou K, Papazoglou D, Bekiari E, et al. (2010) Glycaemic control is correlated with well-being index (WHO-5) in subjects with type 2 diabetes. Exp Clin Endocrinol Diabetes 118(6): 364-367.

21. Yi JP, Vitaliano PP, Smith RE, Yi JC, Weinger K (2008) The role of resilience on psychological adjustment and physical health in patients with diabetes. Br J Health Psychol 13(Pt 2): 311-325.

22. Moskowitz JT, Epel ES, Acree M (2008) Positive affect uniquely predicts lower risk of mortality in people with diabetes. Health Psychol 27(1S): S73-S82.

23. Huffman JC, DuBois CM, Millstein RA, Celano CM, Wexler DJ (2015) Positive psychological interventions for patients with type 2 diabetes: rationale, theoretical model, and intervention development. J Diabetes Res 428349: 1-18.

24. Bolier L, Haverman M, Westerhof GJ, Riper H, Smit F, et al. (2013) Positive psychology interventions: a meta-analysis of randomized controlled studies. BMC Public Health 13: 119.

25. Moskowitz JT, Carrico AW, Duncan LG, Cohn MA, Cheung EO, et al
(2017) Randomized controlled trial of a positive affect intervention for people newly diagnosed with HIV. J Consult Clin Psychol 85(5) 409423

26. Moskowitz JT, Hult JR, Duncan LG, Cohn MA, Maurer S, et al. (2012) A positive affect intervention for people experiencing health-related stress: development and non-randomized pilot test. J Health Psychol 17(5): 676-692.

27. Ogedegbe GO, Foster CB, Wells MT, Allegrante JP, Isen AM, et al. (2012) A randomized controlled trial of positive-affect intervention and medication adherence in hypertensive African Americans. Arch Intern Med 172(4): 322-326

28. Peterson JC, Charlson ME, Hoffman Z, Wells MT, Wong SC, et al. (2012) A randomized controlled trial of positive-affect induction to promote physical activity after percutaneous coronary intervention. Arch Intern Med 172(4): 329-336.

29. Huffman JC, Millstein RA, Mastromauro CA, Moore SV, Celano CM, et al (2016) A positive psychology intervention for patients with an acute coronary syndrome: treatment development and proof-of-concept trial. J Happiness Stud 17(5): 1985-2006.

30. Fredrickson BL (2001) The role of positive emotions in positive psychology. The broaden-and-build theory of positive emotions. Am Psychol 56(3): 218-226.

31. van der Heijden MM, Pouwer F, Romeijnders AC, Pop VJ (2012) Testing the effectiveness of a self-efficacy based exercise intervention for inactive people with type 2 diabetes mellitus: design of a controlled clinical trial. BMC Public Health 12:331.

32. Carlson LE (2012) Mindfulness-based interventions for physical conditions: a narrative review evaluating levels of evidence. ISRN psychiatry 2012: 651583 .

33. Kopf S, Oikonomou D, Hartmann M, Feier F, Lang VF, et al. (2014) Effects of stress reduction on cardiovascular risk factors in type 2 diabetes patients with early kidney disease: results of a randomized controlled trial (HEIDIS). Exp Clin Endocrinol Diabetes 122(6): 341-349.

34. Cohn MA, Pietrucha ME, Saslow LR, Hult JR, Moskowitz JT (2014) An online positive affect skills intervention reduces depression in adults with type 2 diabetes. J Posit Psychol 9(6): 523-534.

35. Steinhardt MA, Brown SA, Dubois SK, Harrison L, Lehrer HM, et al. (2015) A resilience intervention in African-American adults with type 2 diabetes. Am J Health Behav 39(4): 507-518.

36. DuBois CM, Millstein RA, Celano CM, Wexler DJ, Huffman JC (2016) Feasibility and Acceptability of a Positive Psychological Intervention for Patients With Type 2 Diabetes. Prim Care Companion CNS Discord 18(3).

37. Moazzezi M, Moghanloo VA, Moghanloo RA, Pishvaei M (2015) Impact of acceptance and commitment therapy on perceived stress and special health self-efficacy in seven to fifteen-year-old children with diabetes mellitus. Iran J Psychiatry Behav Sci 9(2): 956.

38. Schroevers MJ, Tovote KA, Keers JC, Links TP, Samnderman R, et al. (2015) Individual mindfulness-based cognitive therapy for people with diabetes: A pilot randomized controlled trial. Mindfulness 6(1): 99-110.

39. Gregg JA, Callaghan GM, Hayes SC, Glenn Lawson JL (2007) Improving diabetes self-management through acceptance, mindfulness, and values: a randomized controlled trial. J Consult Clin Psychol 75(2): 336-343.

40. Hartmann M, Kopf S, Kircher C, Lang VF, Djuric A, et al. (2012) Sustained effects of a mindfulness-based stress-reduction intervention in type 2 diabetic patients: design and first results of a randomized controlled trial (the Heidelberger Diabetes and Stress-study). Diabetes Care 35(5): 945-947. 


\section{Current Research in Diabetes \& Obesity Journal}

41. Rosenzweig S, Reibel DK, Greeson JM, Edman JS, Jasser SA, et al. (2007) Mindfulness-based stress reduction is associated with improved glycemic control in type 2 diabetes mellitus: a pilot study. Altern Ther Health Med 13(5): 36-38.
42. Shi Q Ostwald SK, Wang S (2010) Improving glycaemic control selfefficacy and glycaemic control behaviour in Chinese patients with Type 2 diabetes mellitus: randomised controlled trial. J Clin Nurs 19(3-4): 398-404.

\section{Your next submission with Juniper Publishers} will reach you the below assets

- Quality Editorial service

- Swift Peer Review

- Reprints availability

- E-prints Service

- Manuscript Podcast for convenient understanding

- Global attainment for your research

- Manuscript accessibility in different formats

( Pdf, E-pub, Full Text, Audio)

- Unceasing customer service

Track the below URL for one-step submission https://juniperpublishers.com/online-submission.php 